MÉDICOS EM BELÉ/

$$
\begin{array}{r}
\text { TRAJETÓRIAS, PRESTÍC } \\
\text { E PATRIMÔNIO DOCUMEN } \\
\text { PARA UMA HISTÓRIA } \\
\text { POPULAÇÃO E DA FAM }
\end{array}
$$




\section{MÉDICOS EM BELÉM: TRAJETÓRIAS, PRESTIIGIO E PATRIMÔNIO DOCUMENTAL PARA UMA HISTÓRIA DA POPULAÇÃO E DA FAMIILIA}

\section{CRISTINA D O NZA C A N C E L A}




\title{
MÉDICOS EM BELÉM: TRAJETÓRIAS, PRESTÍGIO E PATRIMÔNIO DOCUMENTAL PARA UMA HISTÓRIA DA POPULAÇÃO E DA FAMÍLIA
}

\begin{abstract}
Resumo
O texto discute a formação educacional dos médicos ao longo do século XIX, destacando a importância desta profissão na construção do capital simbólico, do prestígio e da renda na sociedade belenense; e, ainda, de que maneira a adoção de uma profissão liberal permitiu aos jovens doutores maior fluidez nas escolhas de sua alianças matrimoniais em função da maior independência em relação ao patrimônio familiar, uma vez que eles poderiam montar seu próprio porffolio a partir do exercício de suas profissões. Num segundo momento do texto, mostramos como os mapas e relatórios dos médicos sanitaristas constituem-se em um acervo documental importante para a construção da História da População e da Família em Belém, nos ajudando a compreender o perfil da população quanto ao gênero, a geração, a condição social, dentre outras possibilidades que estas fontes nos abrem.
\end{abstract}

Palavras-chave: história da família, medicina, Belém.

\section{DOCTORS IN BELÉM : TRAJECTORIES, PRESTIGE AND DOCUMENTARY PATRIMONY FOR A HISTORY OF THE POPULATION AND THE FAMILY}

\begin{abstract}
This article analyzes the educational background of physicians in Belém through the nineteenth century, focusing at the importance of this profession in the construction of symbolic capital, prestige and income in that society, and also, looking at how this profession enabled to the young doctors a greater decision-making power in their matrimonial alliances due to the greater independence from their family's patrimony, since they could assemble their own portfolio from the exercise of the medicine. The article also shows the importance of the maps and reports of sanitary doctors to the construction of the History of Population and Family History in Belém, helping us to understand the profile of the population in terms of gender, generation, social status, among other research possibilities.
\end{abstract}

Keywords: history of family, medicine, Belém. 


\section{MEDECINS A BELEM : TRAJECTOIRES, PRESTIGE ET PATRIMOINE DOCUMENTAIRE POUR UNE HISTOIRE DE LA POPULATION ET DE LA FAMILLE}

\section{Résumé}

Cet article analyse le formation educationnelle des médecins à Belém au cours du XIX e siècle, en soulignant limportance de cette profession dans la construction du capital symbolique, de prestige et de revenus dans la société, et aussi, comment cette métier a permis à de jeunes médecins plus pouvoir de décision dans leurs alliances matrimoniales en raison de la plus grande indépendance en relatif le patrimoine familial, car ils pourraient monter votre propre portefeuille pour l'exercice de cette profession. Dans une deuxième section, nous montrons l'importance des cartes et rapports des médecins sanitaires pour la construction de l'Histoire de la Population et de la Famille à Belém, pour nous aider à comprendre le profil de la population en termes de genre, de génération, le statut social, et les autres possibilités de recherche.

Mots-clés: histoire de la famille, médecine, Belém.

Endereço da primeira autora para correspondência: Programa de Pós-Graduação em Antropologia, Universidade Federal do Pará. Rua Augusto Correa, 1, Campus Básico. CEP 66075-110, Belém, PA. E-mail: donza@ufpa.br 


\section{INTRODUÇÃO}

A segunda metade do século XIX configura-se em um momento de liquidez econômica na capital paraense, não apenas pela expansão da economia da borracha verificada neste período, mas também pelos caminhos abertos por este negócio. $\mathrm{Na}$ cidade de Belém cresce o número de agências bancárias, e os valores em dinheiro em conta corrente tendem a aumentar no portfolio dos indivíduos, assim como investimentos em seguros de vida e ações. Com o crescimento da cidade e seu aumento populacional, estimulado pela migração nacional e estrangeira, o segmento imobiliário também se expande. Casas de pequenos cômodos são alugadas por preços altos e em ascensão, para reclamação dos inquilinos (Cancela 2008). Todos estes elementos nos ajudam a perceber o aumento da liquidez econômica do período acima referida.

Essas mudanças, de alguma forma, favorecem o crescimento do setor de serviços da cidade, das profissões liberais e do emprego o que, dentre outras consequências, se reflete no aumento das possibilidades de atividade e de renda das camadas mais jovens da população. A formação profissional, aliada ao crescimento e ao fortalecimento das instituições e do setor de serviços, abriu espaço para que esses jovens viessem a trabalhar e ganhar reconhecimento profissional e social, sem necessariamente precisar dos bens de produção familiar para consolidar sua manutenção. Em meio aos grupos mais abastados da sociedade, isto significa dizer que, cada vez mais, os filhos poderiam traçar suas profissões e suas trajetórias a despeito dos bens da familia.
Jovens filhos de proprietários de terra, criadores de gado e donos de engenhos ficavam menos vulneráveis às necessidades da herança, único meio viável para alguns iniciarem e manterem uma nova unidade familiar. Sem uma formação educacional e o exercício de uma profissão, a trajetória pessoal destes indivíduos ficava muito atrelada às possibilidades de dote, herança, terças e ditames familiares, pois os bens da parentela eram fundamentais para o seu estabelecimento. Com essa dependência dos bens familiares, suas decisões, inclusive aquelas relativas à possíveis alianças matrimoniais, ficavam bastante circunscritas à rede de parentesco, ao seu patrimônio e, portanto, aos seus anseios, expectativas e decisões estratégicas.

\section{EDUCAÇÃO, MEDICINA E CASAMENTO}

O sentimento e as decisões pessoais na escolha do nubente que marcam o amor romântico caracterizado como próprio aos séculos XVIII e XIX pela literatura (Macfarlane 1990), precisava ser negociado com as expectativas, os acordos patrimoniais e familiares da rede de parentesco, particularmente quando envolvia terras e gado.

Contudo, a formação profissional e a ascensão a partir de uma carreira profissional poderia significar a formação de uma renda e um patrimônio pessoal, tornando o indivíduo mais independente dos bens familiares o que, de algum modo, poderia abrir possibilidades financeiras para que estes jovens formassem, de forma mais fluida e sem tantas amarras, suas próprias unidades familiares, inclusive a partir de suas escolhas e sentimentos pessoais, a despeito das expectativas do grupo de 
parentesco mais amplo e das questões patrimoniais.

Embora deva-se ressaltar que, muitas vezes, a influência da rede de parentesco pudesse vir a auxiliar na ascensão profissional dos seus membros, favorecendo o acesso a cargos e funções públicas e privadas (Lewin 1993), alguns jovens médicos, advogados e engenheiros, seguiam os caminhos já traçados por seus pais ou parentes próximos, beneficiandose do capital simbólico do nome e da projeção familiar. De qualquer maneira, jovens doutores e bacharéis têm possibilidades de estabelecer suas trajetórias profissionais e pessoais com menor auxilio familiar a partir da consolidação da economia da capital paraense e o aumento do setor de serviços e populacional.

Para que isto ocorresse foi também fundamental que a formação educacional e profissional ganhasse destaque ao longo de todo o oitocentos. Segundo Nazarri (2001), a educação tinha grande importância no século XIX, já que a profissão liberal era praticamente uma exigência para os homens da elite e servia como instrumento de ascensão social para os da classe média. Não é à toa que os filhos dos proprietários passaram a circular com mais freqüência em renomadas escolas estrangeiras e nacionais. Por sua vez, aqueles advindos de famílias com menor posse procuravam na formação educacional e profissional a possibilidade de reconhecimento e melhoria do status social.

Em geral, a formação era realizada em colégios e faculdades de Recife, Rio de Janeiro, Portugal, França, Inglaterra e Bélgica, o que permitia que estes jovens retornassem à capital como bacharéis em medicina, direito e engenharia, as profissões mais procuradas como veremos mais à frente.

A despeito da fortuna familiar, e até mesmo a propósito desta, a busca de uma formação para os descendentes era algo bastante almejado e valorizado socialmente, mesmo que esses não viessem a seguir a carreira escolhida, tendo que depois de formados administrar os negócios da familia (Teruya 2002: 99). Na revista $A$ Semana, notas comentando o estudo dos filhos de famílias da elite local podiam ser corriqueiramente encontradas, como a seguir transcrita:

“No paquete 'Ceará' partiu para o Rio de Janeiro, em cuja faculdade de medicina se vae matricular, o jovem $\mathrm{Mu}-$ rillo Corrêa de Miranda, filho do Dr. Corrêa de Miranda, notário público em Belém."

Muitos desses jovens tornavam-se os primeiros bacharéis da família; outros, no entanto, trilhavam caminhos já traçados pelos pais que, já na primeira metade dos oitocentos, procuraram uma formação profissional, como se observa da lista publicada no Jornal O Diário de Notícias, contendo o nome dos paraenses que freqüentaram as faculdades de direito do Recife e de São Paulo, desde a época da fundação das mesmas. $\mathrm{Na}$ relação são encontrados os sobrenomes de boa parte das famílias mais tradicionais da cidade, como Chermont, Corrêa de Miranda, Leitão da Cunha, Bezerra e Lacerda, para citar apenas algumas delas. ${ }^{2}$

A busca pela formação foi, portanto, uma marca do século XIX, embora, como se tenha dito, nem sempre esses jovens viessem a exercer a profissão, pois, às vezes, 
os filhos dos proprietários passavam a assumir a administração dos bens familiares após a conclusão dos seus estudos, ou mesmo, após a morte dos pais.

Quando do falecimento do doutor Pedro Pereira Chermont Rayol, seus quatro filhos residiam fora da capital trabalhando ou realizando seus estudos em faculdades brasileiras (Borges 1986: 130). Pedro era residente na faculdade de medicina do Rio de Janeiro; Octavio, engenheiro civil, residia em São Paulo, exercendo sua profissão na prefeitura; Heitor, engenheiro civil, também morava em São Paulo, trabalhando na estrada de ferro de Bauru; e finalmente, Alberto, o mais novo, formado em ciências jurídicas e sociais, habitava no Rio de Janeiro. Com a morte do pai, o filho mais velho teve de retornar da capital federal para encaminhar o inventário e administrar os inúmeros bens imobiliários que o pai possuía em Belém e em outras cidades. $^{3}$

Não foi diferente com a trajetória de vida de um de seus primos pela linhagem materna, Pedro Geyselar Chermont de Miranda, filho de Vicente Chermont de Miranda. Após viver na Europa com seu irmão e sua irmã, Pedro regressou a Belém substituindo o pai na administração das fazendas do Marajó e na Companhia Pastoril Paraense de abate e comércio de gado bovino (Borges 1986: 299). Antes dele, seu pai, o paraense Vicente Chermont de Miranda, havia se formado em engenharia na Bélgica e, ao regressar, assumiu a direção do engenho de açúcar da família localizado no Rio Capim, assumindo posteriormente cargos políticos e militares na guarda nacional. Em 1894, comprou grandes fazendas de gado, as quais, como foi referido, foram posteriormente administradas por seu filho, Pedro. ${ }^{4}$

A importância da carreira na medicina como um elemento que permitiu a determinados indivíduos aampliarem seu status social, pode ser também verificada na trajetória do médico Rogério Corrêa de Miranda. Nascido em uma família de proprietários de terras estabelecida em Igarapé-Miri e Abaetetuba, era filho oriundo do segundo casamento do abastado senhor de engenho e oficial da Guarda Nacional, Justo José Corrêa de Miranda com Alexandrina Maria Pinheiro.

Quando Justo José faleceu, em 1878, deixou para seus herdeiros um considerável cabedal econômico, composto de determinados bens, como 32 escravos, terras e dois engenhos movidos à vapor nos distritos de Igarapé-Miri e Abaetetuba, uma rocinha em Cametá, além de dívidas ativas e oito residências em Belém, das quais algumas eram utilizadas para aluguel. Vale ressaltar que a riqueza total de Justo foi avaliada em 147:840\$040 réis. $^{5}$

No processo de partilhas efetuado no inventário de Justo José, observamos que, se por um lado, grande parte dos bens de produção ficou com os herdeiros casados ou maiores de 21 anos, constavam no quinhão de Rogério, nesse momento com 12 anos, apenas três imóveis em Belém, alguns objetos e dívidas ativas. Bens inviáveis para que pudesse seguir com a mesma atividade econômica que seu pai exercia relativa aos engenhos da família. De algum modo, o perfil desta partilha pode nos ajudar a compreender o fato de Rogério ter investido em sua formação educacional e não continuar com a tradição econômica da família 
voltada para as atividades agrícolas. Ao que parece, esta não era a vontade de Justo. Antes de morrer, ele declarou no seu testamento:

"Declaro que deixo na minha terça a minha casa de sobrado da travessa do Passinho, aos meus filhos Rogério, Rachel e Reinaldo para dos seus rendimentos se tirar a educação para elles e depois d'elles educados ou por que não, queiram educar-se, que cheguem todos a maior idade será a dita casa será entregue ao mais velho para entre si se dividirem." ${ }^{\prime 6}$

A declaração de Justo torna-se um indício das transformações que foram ocorrendo no interior de famílias tradicionais locais em meados do século XIX, onde os pais passaram cada vez mais a investirem na educação e instrução dos filhos. Assim, a educação foi o meio pelo qual Rogério pôde construir prestígio social. Anos depois da morte de seu pai, deslocou-se para o Rio de Janeiro, onde estudou medicina. Membro de uma família influente, a conclusão de seu curso e sua volta ao Pará não podia deixar de ser destacada. Informava o periódico:

"Ha dias se acha entre nos, vindo do Rio, onde brilhantemente concluiu seu curso de medicina, o nosso talentoso conterrâneo dr. Rogério Corrêa de Miranda. Que na vida pratica que se lhe abra prasenteira obtenha todos os triumphos desejáveis e as prosperidades de que é digno, são os votos que fazemos ao sauda-lo cordealmente."

No século XIX, ser um profissional liberal carregava uma marcante carga simbólica que permitiu a certos médicos, advogados, letrados etc., a conquista do reconhe- cimento social individual e a continuidade do prestígio do grupo de parentesco ao qual pertenciam (Cancela 2006). Não à toa, o status advindo da medicina foi fundamental para que Rogério estabelecesse laços de parentesco com uma família de fazendeiros abastados da vila de Soure, localizada na Ilha do Marajó: os Bezerra. Dois meses depois da chegada do médico em Belém, temos a seguinte notícia:

"Teve lugar sábado último na Cathedral o casamento do ilustre médico dr. Rogério Corrêa de Miranda com a exm ${ }^{a}$ senhora D. Maria Luiza Bezerra, filha do honrado coronel Francisco Bezerra de Moraes Rocha e sobrinha do distincto chefe democrata dr. Demetrio Bezerra.

$\mathrm{O}$ ato religioso foi concorrido pelo que há demais selecto na sociedade paraense, sendo celebrante o $\mathrm{rvm}^{\circ}$ cônego dr. Marcio Ribeiro.

Felicitando os recém-casados e seus ilustres parentes desejamolhes todas as felicidades."

Neste caso, o jornal buscou enfatizar uma série de elementos de distinção que destacam a condição social dos envolvidos no casamento: a Cathedral como o local onde ocorreu a cerimônia religiosa, o público selecto que esteve presente e a referência a Rogério como um ilustre médico (Cancela 2008).

Portanto, consideramos que o fato de pertencer a uma família tradicional de Igarapé-Miri e Abaetetuba, somado à sua formação em medicina e a respeitabilidade inerente a esta profissão, tornaram Rogério um sujeito conceituado socialmente e "bem-visto" perante os pais da noiva. 
Tudo indica que, apesar da sua formação, ele não deixou de vincular-se a outras atividades econômicas, já que nos últimos anos do século XIX tornou-se sócio da marchantaria que seu irmão, Reinaldo Corrêa de Miranda, estabeleceu em Soure, tendo este último também casado com uma representante da família Bezerra, de nome Malvina, filha de Antônio Bezerra da Rocha Moraes. ${ }^{9}$

A efetuação de matrimônios possibilitou que Rogério e seu irmão se deslocassem para Soure, região na qual os Bezerra detinham grande influência, onde puderam adentrar em um tipo de comércio que era comum na ilha do Marajó e que poderia lhes render bons lucros.

Ademais, com a morte de seu sogro, em 1912, Rogério também teve que administrar os bens que foram deixados para a sua esposa. O fato de herdar um patrimônio composto de terras e benfeitorias em Soure, touros, ovelhas, porcos e várias cabeças de gado vacum e cavalar, ${ }^{10}$ permite-nos pensar que o médico Rogério Corrêa de Miranda, filho de um senhor de engenho, também tenha enveredado pela pecuária, o que, de fato, corrobora a idéia de que nem sempre estes profissionais atuavam em atividades correspondentes às suas formações educacionais, sendo que muitas vezes passavam a assumir os negócios da rede familiar a qual estavam inseridos.

Por vezes, esses profissionais liberais não advinham de famílias tradicionais ou com fortuna, mas através do exercício da carreira conseguiam estabelecer-se e construir um capital simbólico que lhes abria as portas da sociedade local. O casa- mento poderia se mostrar um recurso importante neste processo, ampliando e consolidando o status social e o prestígio desses profissionais, alguns deles migrantes possivelmente atraídos pela expansão econômica da capital. Indivíduos como o americano Julio Weinberg, de 37 anos de idade, doutor em medicina, que se casou com Marcionilla, 22 anos, filha de um próspero proprietário de terras e criador de gado da Ilha do Marajó, Anthonio Theodomiro Ferreira Penna. Anteriormente, sua irmã, Leonilla Teixeira Penna, 18 anos, havia se casado com o baiano Napoleão Simões de Oliveira, 38 anos, que exercia a função de desembargador do Tribunal de Justiça do Pará. Estas alianças mostram como duas irmãs pertencentes a uma tradicional e rica familia de proprietários de terra e pecuaristas, os Ferreira Penna, casaram-se com migrantes de famílias sem tradição no Estado, mas com uma sólida carreira liberal, que lhes possibilitava prestígio, reconhecimento e status social, a ponto de estabelecerem aliança com mulheres abastadas da sociedade local o que, como em uma via de mão dupla, também poderia ampliar, ainda mais, o capital simbólico destes profissionais e das famílias às quais eles passavam a fazer parte. ${ }^{11}$

É bem provável que nem todos aqueles que enveredaram pela medicina conseguiram acumular prestígio e fortuna como os profissionais anteriormente referidos. Contudo, esta formação favorecia uma condição social confortável aos indivíduos que nela ingressavam, mesmo considerando que alguns deles vinham de famílias proprietárias com largo patrimônio. Quando verificamos o alis- 
tamento eleitoral a partir do ano de 1881, temos a declaração da renda daqueles que procuravam se alistar. ${ }^{12}$ Deste modo, verificamos que os médicos figuravam entre aqueles que estavam nos patamares mais altos de renda. Pessoas como Jaime Pombo Bricio, 39 anos, casado, filho de Jaime David Bricio e morador da Estrada de Nazaré, que declarou uma renda de 3:000\$000, no alistamento eleitoral de 1881. Ele era membro da tradicional família Henriques Pombo, que veio da Galizia e chegou ao Pará na segunda metade do século XVIII, proprietária de terras na Ilha Mexiana, criadores de gado, donos de inúmeros imóveis em Belém e terras com estradas de seringas (Cancela 2009).

Ou mesmo nomes como o de José da Gama Malcher, profissional formado em medicina e que fez carreira na política, tendo sido presidente da câmara municipal em diversas legislaturas e vicepresidente da província do Pará, ao final da década de 1870 e início de $1880 .{ }^{13}$ Com 67 anos à época do alistamento eleitoral de 1881, era casado, filho de Aniceto Francisco Malcher, e morador da Estrada de Nazaré, tendo declarado a renda de 4:000\$000. Vale lembrar que sua filha, Anna Cândida Malcher Cunha, casou-se com João Gualberto da Costa Cunha, comerciante, membro de uma família proprietária maranhense, e dono de uma das maiores firmas comerciais ligadas diretamente ao comércio de exportação da borracha, a "Darlindo Rocha \& Companbia", ${ }^{14}$ tendo ainda participado da instituição do Banco Emissor, em Belém (Weinstein 1993). Vemos aqui como esta família de um reconhecido médico paraense estabeleceu aliança matrimonial com um migrante, neste caso, já vindo de uma família de posses no Maranhão, envolvido com o negócio da borracha. Percebe-se neste arranjo aquilo de que falávamos sobre como as relações matrimoniais uniam familias tradicionais paraenses com indivíduos recém chegados à província, que enriqueciam, ou tinham suas fortunas expandidas com a liquidez trazida pelo comércio da borracha.

Voltando à renda dos médicos declaradas nos alistamentos eleitorais, destacamos, ainda, o de Cipriano José dos Santos que tinha o nome homônimo de seu pai -, com 28 anos de idade, casado, morador à Rua São João, nas mediações do $1^{\circ}$ Distrito, na chamada Cidade Velha, que declarou a renda de 6:000\$000, a maior dentre os médicos arrolados no alistamento. Cipriano foi formado em medicina pela Faculdade da Bahia, sendo inspetor do serviço sanitário na década de 1880. Apoiava Lauro Sodré e o Partido Republicano Federal, sendo proprietário e fundador do jornal $A$ Folha do Norte, que começou a circular em 1896, tendo uma expressiva projeção na vida e nos acontecimentos políticos da cidade (Silva 2009; Borges 1986).

Por fim, destacamos o médico Aprigio Antonio da Costa Andrade, único solteiro da relação dos alistados, com 29 anos de idade, tendo declarado a menor renda no valor de 2:000\$000, no ano de 1883. Em 1884, Aprigio encontrava-se entre os facultativos que foram chamados pelo presidente da província, visconde de Maracajú, para fazer a vacinação de varíola na população da cidade. ${ }^{15}$

A propósito da projeção social e do capital simbólico que o exercício da medicina 
agregava, como podemos observar da renda declarada pelos profissionais acima referidos, que constavam entre as mais altas do alistamento eleitoral, nem sempre a medicina era a formação mais almejada. A procura pelo direito parecia ser mais acentuada à época. Não temos como aferir com precisão esta informação, mas algumas fontes nos indicam a pertinência desse dado. Quando trabalhamos com os registros civis de casamento de Belém, encontramos 56 médicos e acadêmicos de medicina, enquanto o número de advogados, bacharéis e acadêmicos de direiro alcançavam o patamar de 114 indivíduos. Os nubentes formados em engenharia, nas mais diversas áreas, chegaram a 43 indivíduos. A formação em direito parecia prevalecer entre as profissões liberais do período, pelo menos em meio àqueles que estavam estabelecendo suas alianças matrimoniais. Para se ter uma idéia, tirando as profissões liberais aqui arroladas, como a de advogado, médico e engenheiro, as demais alcançavam 139 indivíduos, entre professores, dentistas, agrônomos, geógrafos, farmacêuticos, químicos e arquitetos. Portanto, uma quantidade nada expressiva, quando consideramos que o número de pessoas formadas no conjunto de todas essas profissões era apenas um pouco maior do que aquele encontrado unicamente entre os que se formaram em direito.

De todo modo, vemos que os indivíduos que exerciam profissões liberais ainda não eram muitos, afinal os registros somaram 6.895 casamentos civis e, dentre os noivos, apenas 5\% foram arrolados nas mais diversas profissões liberais sendo que, dentre essas, a medicina vinha logo em seguida ao direito. Notamos assim um número não muito expressivo de profissionais liberais quando comparado a indivíduos com outras atividades. Esse cenário sugere o prestígio que esses indivíduos poderiam alcançar em uma sociedade onde a formação e a construção de uma carreira liberal ainda não era para muitos.

O acervo documental relativo aos registros civis de casamento nos permite ainda conhecer a idade em que as pessoas estavam se casando. Em particular, quando nos atemos aos médicos, vemos que a idade de casamento variou entre 21 a 53 anos de idade, sendo que a maior concentração ocorreu entre aqueles que se casaram entre 26 e 34 anos de idade, num total de 35 , enquanto este número era de apenas 12. Este número é justificável pois as mulheres costumavam casar mais cedo que os homens. Para se ter uma idéia, 42 mulheres casadas com médicos tinham até 25 anos (destas 11 tinham até 19 anos de idade), dentre os médicos, aqueles que casaram com menos de 25 anos somam apenas 7. Por outro lado, somente 2 mulheres casaram com mais de 30 anos, enquanto entre os homens este número era de 27 noivos.

$\mathrm{Na}$ verdade, no que se refere à idade, o padrão encontrado entre as alianças dos profissionais de medicina não variou em relação àquele verificado para o conjunto da população de Belém (Barroso \& Cancela 2010). Os homens casavam-se mais tarde que as mulheres e muitos deles também estabeleciam matrimônio depois dos 35 anos de idade, o que para as mulheres era uma realidade bem distante. 
Podemos inferir, dentre as inúmeras questões culturais que permeiam este padrão de idade de casamento, um fator que nos aproxima dos argumentos desse texto, que é o fato dos homens terem que ter patrimônio e renda para iniciar uma nova família tendo em vista seu papel cultural de provedor. As expectativas sociais em torno do masculino atualizam práticas e valores que lhes atribuem necessidade de manter a casa e o seu sustento, o que para jovens profissionais de camadas médias e altas, em particular, poderia significar o investimento de tempo em um projeto pessoal próprio de formação educacional e consolidação profissional e, só posteriormente, a possibilidade de casamento, adiando a idade ao casar dos homens. Como ressalta Nazarri, a principal mudança ocorrida no final do século XIX e início do XX, em relação ao papel do homem no casamento estava associada ao fato dele não ser mais considerado aquele que vai administrar seus bens e o dote recebido de sua mulher; mas, sim, aquele que vai prover os bens para o seu lar, protegendo a esposa e os filhos (Nazzari 2001).

Não podemos esquecer que, diferentemente da atualidade, o papel das mulheres de camadas altas e médias no mercado de trabalho, embora se fizesse presente, era ainda bastante restrito, não se constituindo em uma realidade comum aos padrões da época (Maluf 1998). A despeito da formação educacional feminina (Bezerra Neto 1995; Cancela 2008), não havia a expectativa social de que uma mulher oriunda desses grupos abastados poderia vir a exercer uma profissão e prover o domicílio juntamente com o marido, um processo que foi se tornando cada vez mais comum na atualidade (Berquó 1998). Portanto, por mais que o patrimônio de muitas mulheres, ou mesmo as atividades que elas exerciam pudessem vir a sustentar na prática uma família, esse não era o comportamento mais comum à época para esses segmentos abastados.

\section{ACERVO DOCUMENTAL, RELATÓRIOS MÉDICOS, HISTÓRIA DA POPULAÇÃO E DA FAMÍLIA}

Para além das relações entre família, casamento, formação profissional e medicina, acima discutidas, que nos mostram muito do patrimônio simbólico e do status social dos médicos e de seus familiares, estes profissionais nos legaram, como já referimos, fontes fundamentais para a construção e compreensão da História da População e da Família. Os médicos, em particular os higienistas, ao executarem a vacinação nas casas dos inúmeros distritos da cidade, elaboravam um mapa dos domicílios, que continham dados sobre a rua atendida, as casas, o número de pessoas existentes em cada uma delas e, ainda, o gênero e a idade. Nessa seção do texto veremos não a trajetória ou as alianças matrimoniais dos profissionais da medicina, mas de que modo estes profissionais nos ajudam a ter acesso à informações que servem de fonte à compreensão da História da Família e do Casamento da população da cidade em que eles exerceram suas atividades. Se em um primeiro momento discutimos o casamento, a família, o patrimônio e a formação educacional dos médicos em suas relações pessoais e de sociabilidade, 
a partir de agora veremos como eles nos auxiliam na construção de dados sobre famílias e domicílios.

Dentre as informações que podemos aferir a partir dos relatórios médicos, destacamos inicialmente os dados referentes à média de moradores por domicílio, da que constava nos mapas o número de pessoas vacinadas em cada casa. Este dado pode ser cruzado com o gênero e a geração dessas pessoas, marcadores sociais importantes para termos uma idéia da distribuição da população na cidade e seu perfil, o que é fundamental em um período onde os dados quantitativos nem sempre são recorrentes e possuem inúmeras limitações.

Num período em que a situação da saúde pública em Belém era crítica, fruto da epidemia de varíola que a atingia, a carreira médica ia ganhando cada vez mais status e importância na sociedade local. Não à toa, as autoridades políticas da época passaram a convocar os serviços destes profissionais, que, por sua vez, utilizaram seus saberes e técnicas científicas na campanha de combate às epidemias, adotando medidas sanitaristas que abrangeram parte da população.

Foi o que ocorreu no ano de 1884, quando o presidente da província, Visconde de Maracajú, preocupado com tal surto de varíola, afirmava em relatório ter adotado medidas mais profícuas e específicas no combate ao flagelo. Para isso, convocou alguns médicos que residiam na capital a prestarem seus serviços na guerra contra o "terrível hóspede" que atingia a urbe. ${ }^{16}$

A partir dos mapas elaborados por médicos como José Veríssimo de Matos, que percorreu as ruas do $4^{\circ}$ distrito entre os dias 22 a 26 de janeiro de 1884, ficamos sabendo que, das 75 pessoas vacinadas, 13 eram adultas e 63 eram menores, sendo que, do total, 52 eram do sexo feminino e 24 do masculino. No mesmo mapa ele discrimina o número de pessoas vacinadas por domicílio o que, como referimos acima, pode ser um indicativo da quantidade de pessoas que habitava cada casa, nos ajudando a criar uma média dos moradores. Evidentemente este seria apenas um indicativo, pois não temos como saber se as pessoas vacinadas no domicílio viviam efetivamente nele, ou mesmo que tipo de relação de parentesco elas possuíam entre si. Como dissemos, os dados médicos funcionam como um indicativo deste perfil.

Ainda analisando as possibilidades de análise legada por estes profissionais, destacamos que ao determinar a casa onde foi efetivada a vacinação, os médi$\cos$ as definiam a partir de um nome, que poderia ser o do morador chefe do domicílio, ou da pessoa que atendeu a equipe de profissionais da vacinação. Os nomes indicados podem nos dar pistas sobre a condição social dos moradores visitados e sua distribuição no espaço citadino. Assim, o médico aponta em seu mapa a visita à casa do doutor João Coelho, que ficava próxima à residência do major Costa e do capitão Menezes, ao lado de alguém chamado Paiva, de quem não temos idéia da profissão, mas pela forma de identificação não deveria ser um indivíduo com renda ou posição social considerada no olhar médico, o que podemos aferir pela forma de registrá-lo simplesmente por um nome, enquanto 
os demais foram identificados com seus títulos e suas patentes. ${ }^{17}$

No relatório de Américo Santa Roza, que realizou visitas para vacinação no mesmo período de José Veríssimo de Matos, os mesmos dados podem ser observados, tendo o médico vacinado 185 pessoas nas ruas do $1^{\circ}$ distrito, onde percorreu as seguintes vias: Rua do Ferreira, Dr. Malcher, Travessa do Atalaya, Largo São João, Rua do Norte, Travessa da Rosa, Porto do Sal, Largo da Sé e Estrada de São José.

A partir de seu mapa, no entanto, um dado a mais se apresenta relativo às mulheres. Em uma das residências morava dona Olivia Mattozinhos que, com 15 anos de idade já era tratada de dona. Ela morava ao lado de outra mulher que é simplesmente referida como Lucinda, com 23 anos, mais velha que Olivia e não tinha seu nome seguido da expressão de tratamento dona. Sabemos que esta expressão é indicativa de condição social dos indivíduos assim chamados, o que nos mostra a convivência em um mesmo espaço urbano de mulheres com renda e prestígio diferenciado. Aliás, na casa de número 54, onde morava Lucinda, foram também vacinados: João de 40 anos, Mathilde de 21 anos, Raymundo Espindola, 27 anos, Anna Espindola, 27 anos, e mais treze crianças. Como alertamos não temos como saber se estas pessoas tinham algum tipo de relação de parentesco, ou mesmo, se elas viviam todas juntas, mas de toda forma, caso estas pessoas vivessem neste domicílio vimos que nele moravam 18 pessoas. ${ }^{18}$ Alie-se a isto o fato de nenhum ser referido a partir de títulos, patentes ou expressões como dona, ficando a sugestão de que se tratava de um domicílio de pessoas com pouca renda e que, possivelmente, conviviam em um espaço a ser dividido entre 18 indivíduos.

Da mesma forma, o médico sanitarista Antonio Rogério de Gouveia Freire, visitou as ruas do $4^{\circ}$ Distrito e, a partir de seu relatório a presença feminina pode ser analisada. Isto porque, do total de $42 \mathrm{ca}-$ sas visitadas, em 11 delas o nome da pessoa referida para discriminar o domicílio foi de alguém do sexo feminino e, em 35 (trinta e cinco) residências, a referência foi feita a partir do nome de um homem. ${ }^{19}$ Podemos inferir deste dado, a existência de mulheres morando sozinhas, ou mesmo com parentes e agregados, mas sem marido, nestas residências em que elas eram a referência para identificação, um arranjo doméstico bastante presente ao longo do século XIX (Kuznesof 1980). O número de domićlios com este perfil chegava a $31 \%$ do total de residências. Esse número é bastante expressivo se pensarmos que essas moradias localizavam-se em uma das áreas mais nobres e ricas da cidade próximo as estradas de Nazaré e São Jerônimo. Algumas dessas mulheres foram relacionadas como viúvas, outras com nome e sobrenome de família, e há ainda aquelas descritas apenas pelos primeiros nomes, indicando serem pessoas pobres, sem linhagem tradicional, como ocorria nos documentos encontrados para outras capitais (Dias 1995).

Estes mapas e relatórios médicos também abrem possibilidades de análise para se conhecer as condições em que se dava a moradia da população e das famílias. É o que podemos depreender do relatório do Dr. Manoel de Moraes Bittencourt, 
um higienista que também chegou a ser vereador entre os anos de 1887/1889 (Cruz s/d: 702). Manoel realizou visitas em diversos domicílios, no ano de 1884 , percorrendo as ruas do $2^{\circ}$ distrito da capital, formado pelo bairro da Campina. Diferentemente dos outros sanitaristas citados acima, ele não produziu um mapa detalhado sobre as pessoas de cada domicílio, mas seu relatório chama a atenção pelo fato de a denominação casa abranger não somente as habitações particulares, mas também lojas de fazenda e molhados, barbearias, hotéis, casas de pasto, oficinas de sapato, alfaiatarias, botequins etc., sendo que muitas das lojas comerciais também continham, conjuntamente, espaços de moradia não apenas do proprietário e sua família, mas também de trabalhadores.

Ademais, a inspeção realizada pelo Dr. Moraes Bittencourt nos permite compreende determinados aspectos da vida urbana na capital paraense num contexto de crescimento econômico amazônico provocado pelo comércio gomífero em expansão. Como já foi ressaltado, o intenso fluxo de migrantes que chegavam à Belém incrementou o surgimento de diversas moradias que eram procuradas por estes sujeitos. Os dados levantados pelo médico sanitarista ajudam na compreensão desse cenário.

Nos dias 25, 26 e 27 de julho de 1884 ele visitou 55 domicílios situados na Campina, onde habitavam um universo de 335 pessoas. $\mathrm{Na}$ Travessa da Piedade foram examinadas 24 casas particulares e 4 vendas, tendo chamado a atenção para um domicílio que terminava "por uma série de quartos pequenos e immundos." $\mathrm{Na}$
Travessa da Princesa, foram vistoriados três estâncias de madeiras e duas cubículos, sendo um com 11 quartos e outro com sete. Outro ponto a ser destacado refere-se ao Beco da Serraria, onde foram inspecionadas uma casa particular e uma venda, sendo que esta última continha "seis quartos pequenos humidos e alugados a diversas pessôas." 20

Além de casas particulares, Manoel Moraes Bittencourt também relatou as visitas realizadas a alguns dos hotéis do distrito, espaços que neste período também eram procurados pelos migrantes que se deslocavam para a região amazônica em busca de trabalho. Sobre o Hotel Amazonas, por exemplo, situado no largo da Misericórdia e vistoriado em agosto daquele ano, o médico o considerava como detentor de "todos os predicados para ser considerado um verdadeiro chiqueiro." ${ }^{21}$

É evidente que ao detalhar as condições das habitações vistoriadas, a intenção dos médicos sanitaristas era chamar a atenção das autoridades para questões relacionadas à higiene e saneamento da cidade. Por outro lado, os relatórios apresentados oferecem uma noção dos diferentes espaços particulares que serviam de moradia à população local e aos migrantes que se estabeleciam na capital paraense, onde podemos compreender a situação de habitação e a condição social dessa população, além de nos permitir visualizar também a urbanização existente e seus limites em um dos primeiros bairros da capital, o da Campina. 


\section{CONSIDERAÇÕES FINAIS}

Observamos de que modo, a partir dos mapas elaborados por estes médicos, temos como levantar informações importantes que nos ajudam a conhecer o perfil socioeconômico da população. Evidentemente, este acervo documental não foi, à época, elaborado com este propósito. A preocupação destes profissionais, engajados em campanhas de profilaxia, era vacinar as pessoas contra a varíola, além de arejar, desodorizar e viabilizar a circulação urbana, com vistas à salubridade, o que se encaixava nas preocupações do período subscritas pela teoria dos miasmas e das descobertas das causas microbianas de inúmeras doenças. As moléstias ocorridas no século XIX, como a febre amarela, a varíola e o cólera se apresentavam de forma contundente nas pautas de justificativa da necessidade de reforma urbana articulada à reforma sanitária aliada ao discurso da modernidade, da urbanização e da racionalidade administrativa e técnica (Chaloub1996, Ritzmann 1997, Beltrão 2004, Amaral 2006, Silva 2009, Sarges 2002). Todavia, a propósito da proposta original, podemos partir deste acervo documental para conhecermos um pouco mais sobre a população da cidade, seu perfil quanto ao gênero, a idade, a condição social, a situação de moradia e a urbanização da capital.

Da mesma forma, o rastreamento de outras fontes como inventários, testamentos, jornais, registros de casamento e alistamentos eleitorais, nos ajudam a conhecer mais densamente as trajetórias pessoais, o patrimônio pessoal e familiar, as alianças matrimoniais, os signos de prestígio e condição socioeconomica daqueles que procuraram a formação médica em Belém. Vimos que a propósito da emergência notada no século XIX, da formação educacional, da ampliação do setor de serviços e do aumento populacional, exigindo um maior número de profissionais liberais, estes ainda compunham uma parcela não tão expressiva em relação ao conjunto da população. Talvez esse fato lhes agregasse um prestígio ainda maior; de todo modo, como destacamos, a renda destes profissionais, em particular dos médicos, encontrava-se entre as maiores declaradas nas listagens eleitorais. Por sua vez, vimos também que poucos deles casaram-se com idade abaixo dos 25 anos, mantendo um padrão que se repete para o conjunto dos homens com diversas atividades. Esse padrão de idade tardia de casamento, quando comparado à feminina, sugere a necessidade de primeiro investir em uma formação educacional e na consolidação do nome e da carreira profissional, a fim de assegurar o provimento de uma nova família. Por vezes, a formação não era exercida ou continuada em função da administração dos negócios familiares; por vezes, a medicina era o caminho para aqueles que não vinham de famílias tradicionais da cidade, conseguindo através dela a ascensão social e a consolidação de um certo status social na sociedade paraense.

Esses são fragmentos de histórias que podemos conhecer através de documentos múltiplos que nos foram legados e conservados. Sem a conservação, guarda e acesso criterioso a esse acervo documental, a história desses profissionais da medicina ficaria invibilizada em alguns de seus aspectos. Temos nos arquivos de 
nossa cidade um patrimônio documental fundamental não apenas para a construção da trajetória da medicina e dos médicos no Pará, mas também para a História da População e da Família.

\section{NOTAS}

${ }^{1}$ Revista A Semana. vo 1, 15 de março de $1919, n^{\circ} 51$.

${ }^{2}$ Fundação Cultural Tancredo Neves (CENTUR). Diário de Notícias. 27 de abril de 1890, p. 02.

3 Centro de Memória da Amazônia/UFPA. Cartório Odon. Inventário Pedro Pereira de Chermont Raiol, 1929.

${ }^{4}$ Fundação Cultural Tancredo Neves (CENTUR). Revista do Instituto Histórico e Geográfico do Pará (IHGPA). Catálogo da $1^{\circ}$ Série de uma galeria histórica - Belém - Imprensa Official do Estado do Pará, 1918. p. 23-24.

5 CMA/UFPA. Cartório Odon. Inventário de Justo José Corrêa de Miranda. 1878.

6 Traslado de testamento existente no Inventário de Justo Jozé Corrêa de Miranda: CMA/ UFPA. Cartório Odon. Inventário de Justo Jozé Corrêa de Miranda, 1878.

7 Jornal O Democrata, 9 de fevereiro de 1893.

8 Jornal O Democrata, 11 de abril de 1893.

9 Irmão de Francisco de Bezerra de Moraes Rocha.

${ }^{10}$ Cf. CMA/UFPA. Cartório Odon. Inventário de Francisco Bezerra de Moraes Rocha, 1912.

11 CMA/UFPA. Cartório Odon. Inventário Anthonio Theodomiro Ferreira Penna, 1899.

${ }^{12}$ CMA/UFPA. Banco de dados do alistamento eleitoral. Fundo do Judiciário. Anos limites 1881-1889. Livros de registro do $3^{\circ}$ Distrito Criminal.
${ }^{13}$ Relatórios de Presidentes de Província (1830-1930). Pará. Relatorio com que ao exm. sr. dr. José da Gama Malcher, 1.o vice-presidente, passou a administração da provincia do Pará o exm. sr. dr. João Capistrano Bandeira de Mello Filho em 9 de março de 1878. Pará, Typ. Guttemberg, 1878. Disponível em: http:/ /www.crl.edu/ pt-br/brazil/provincial/par\%C3\%A1. Acesso em 31 de agosto de 2010.

${ }^{14} \mathrm{CMA} / \mathrm{UFPA}$.Cartório Odon. Inventário João Gualberto da Costa Cunha, 1908.

15 Relatórios de Presidentes de Província (1830-1930). Pará. Relatorio com que o exm.o snr. general visconde de Maracajú passou a administração da provincia ao 2.0 vice-presidente, exm.o snr. dr. José de Araujo Roso Danin, no dia 24 de junho de 1884. Pará, Typ. de Francisco da Costa Junior, 1884. Disponível em: http://www.crl.edu/pt-br/ brazil/provincial $/$ par $\%$ C3\%A1. Acesso em 31 de agosto de 2010.

16 Relatórios de Presidentes de Província (1830-1930), Pará. Relatório com que o exm.o snr. general visconde de Maracajú passou a administração da provincia ao 2.o vice-presidente, exm.o snr. dr. José de Araujo Roso Danin, no dia 24 de junho de 1884. Pará, Typ. de Francisco da Costa Junior, 1884. Disponível em: http://www.crl.edu/pt-br/ brazil/provincial/par\% $\%$ C3\%A1. Acesso em 30 de agosto de 2010.

${ }^{17}$ Arquivo Público do Estado do Pará. Fundo: Secretaria da Presidência da Província. Série 13. Ofícios.Caixa: 409. Ofícios da Inspetoria de Saúde Pública do Pará. doc.8.

${ }^{18}$ APEP. Fundo: Secretaria da Presidência da Província.Série 13. Ofícios. Caixa: 409. Ofícios da Inspetoria de Saúde Pública do Pará. doc. 9.

${ }^{19}$ Arquivo Público do Estado do Pará. Fundo: Secretaria da Presidência da Província. Série 13. Ofícios.Caixa: 409. Ofícios da Ins- 
petoria de Saúde Pública do Pará. Relação de pessoas vacinadas no $4^{\circ}$ distrito de 23 a 26 de janeiro de 1884 e28 de janeiro a 2 de fevereiro do mesmo ano.

${ }^{20}$ APEP. Fundo: Secretaria da Presidência da Província. Ofícios da Inspetoria de Saúde Pública do Pará. Série 13. Ofícios.Caixa: 409. Relatório das visitas realizadas no distrito da Campina pelo Dr. Manoel de Moraes Bittencourt nos dias 25,26 e 27 de Julho de 1884.

${ }^{21}$ APEP. Fundo: Secretaria da Presidência da Província.Ofícios da Inspetoria de Saúde Pública do Pará. Série 13. Ofícios.Caixa: 409. Relatório das visitas domicilirares feitas do 10 a 20 de agosto de1884.

\section{REFERÊNCIAS}

Amaral, A. de S. 2006. Vamos à vacina? Doenças, saúde e práticas médico-sanitárias em Belém (19041911). Dissertação de Mestrado. Programa de Pós Graduação em História Social da Amazônia, Universidade Federal do Pará, Brasil.

Barroso, D. S. \& C. D. Cancela. 2010. Imigração Portuguesa e Casamento: um olhar a partir do gênero, da geração e da atividade (Belém, 1908-1920), in Entre Mares: o Brasil dos Portugueses. Organizado por M. N. Sarges, F. Sousa, M. I. Matos, A. O. Vieira Júnior \& C. D. Cancela, pp. 32-41. Belém: Paka-Tatu.

Beltrão, J. F. 2004. Cólera: o flagelo da Belém do Grão-Pará. Belém: Museu Paraense Emilio Goeldi; Universidade Federal do Pará.

Berquó, E. 1998. Arranjos familiares no Brasil: uma visão demográfica, in História da vida privada no Brasil: contrastes da intimidade contemporânea. Editado por F. Novaes \& L. Schwarcz. São Paulo: Companhia das Letras.

Bezerra Neto, J. M. 1995. O asilo Lyndo e protetor: Práticas e representações sociais sobre a educação feminina. Belém (1870-1888), in A mulher existe? Uma contribuição ao estudo da mulher e do gênero na Amazônia. Organizado por
M.L.M. Alvarez \& M.A. D'Incao, pp. 3-25. Belém: CEPEM.

Borges, R. 1986. Vultos Notáveis do Pará. $2^{a}$ ed. Belém: CEJUP.

Cancela, C. D. 2006. Casamento e relações familiares na economia da borracha. Belém 1870-1920. Tese de Doutorado. Programa de Pós-Graduação em História Econômica, Universidade de São Paulo, Brasil.

2008. Uma cidade...muitas cidades: Belém na economia da borracha, in Conheça Belém, co-memore o Pará. Organizado por J. F. Beltrão \& A. O. Vieira Júnior, pp 79-81. Belém: EDUFPA.

.2009. Famílias de elite: transformação da riqueza e alianças matrimoniais. Belém, 1870-1920, Topoi: Revista de História 10(18): 24-38.

Chaloub, S. 1996. Cidade febril: corticos e epidemias na corte imperial. São Paulo: Companhia das Letras.

Cruz, E. s/d. Historia do Pará. v.2. Belém: UFPA.

Dias, M. O. L. da S. 1995. Quotidiano epoder em São Paulo no século XIX. São Paulo: Brasiliense.

Kuznesof, E. 1980. Household composition and headship as related to changes in made of production: São Paulo, 1765 to 1836 , in Comparative studies in society and History 22 (1):78-108.

Lewin, L. 1993. Politica e parentela na Paraíba: um estudo de caso de oligarquia de base familiar. Rio de Janeiro: Record. Macfarlane, A. 1990. História do casamento e do amor. São Paulo: Companhia das Letras.

Maluf, M. \& M. L. Mott. 1998. Recônditos do mundo feminino, in História da vida privada no Brasil: república da belle époque à era do rádio. Organizado por N. Sevcenko, pp. 367-421. São Paulo: Companhia das Letras.

Nazzari, M. 2001. O desaparecimento do dote: mul- 
her, familias e mudança social em São Paulo, 16001900. São Paulo: Companhia das Letras.

Ritzmann, I. G. 1997. Belém: Cidade Miasmática. Dissertação de Mestrado. Programa de PósGraduação em História Social, Pontifícia Universidade Católica, São Paulo, Brasil.

Sarges, M. de N. 2002. Fincando uma Tradição Colonial na República: Arthur Vianna e Antônio Lemos, in Terra Matura: historiografia e bistória social na Amazônia. Organizado por J. M.Bezerra Neto \& D. Guzmán, pp. 97108. Belém: Paka-Tatu.

Silva, J. N. da S. 2009. Da Mereba-ayba à Variola: isolamento, vacina e intolerância popular em Belém do Pará, 1884 -1904. Dissertação de Mestrado. Programa de Pós-Graduação em História Social da Amazônia, Universidade Federal do Pará, Brasil.

Teruya, M. 2002. Trajetória sertaneja: um século de poder e dispersão familiar na Paraíba. Tese de Doutorado. Programa de Pós-Graduação em História Social, Universidade de São Paulo, Brasil..

Weinstein, B. 1993. A borracha na Amazônia: expansão e decadência (1850-1920). São Paulo: HUCITEC/EDUSP.

Recebido em 20/02/2013.

Aprovado em 12/03/2013. 